\title{
Re-Examining Regional Total-Factor Water Efficiency and Its Determinants in China: A Parametric Distance Function Approach
}

\author{
Jiao Zheng ${ }^{1,2}$, Hengquan Zhang ${ }^{1}$ and Zhencheng Xing ${ }^{1,3, * \mathbb{D}}$ \\ 1 School of Business, Hohai University, Nanjing 211100, China; zhengjiao@sxu.edu.cn (J.Z.); \\ hqzhang630@163.com (H.Z.) \\ 2 Construction Engineering Management Department, Shanxi University, Taiyuan 030013, China \\ 3 Department of Geographical Sciences, University of Maryland, College Park, MD 20740, USA \\ * Correspondence: xzc@hhu.edu.cn; Tel.: +86-25-6851-4818
}

Received: 20 July 2018; Accepted: 17 September 2018; Published: 20 September 2018

\begin{abstract}
It is accepted that improving water efficiency is a key task for China in achieving water sustainability, as the knowledge of water efficiency and its determinants can provide critical information for water policy formulation. To this end, this paper presents a parametric frontier approach to analyze water efficiency performance and its influencing factors in one step. The proposed approach first introduces the Shephard water distance function to construct total-factor water efficiency (TFWE) index and then adopts the stochastic frontier analysis (SFA) technique to compute the index and its determinants. A case study of regions in China from 2000 to 2015 is presented. The main findings are summarized as follows: (1) Both the overall China and most of the regions still have room for improvement in water efficiency. SFA and data envelopment analysis (DEA) might lead to different results in benchmarking water efficiency. Moreover, SFA has higher discriminating power than DEA in this regard. (2) There exists significant disparity of water efficiency among the regions of China, and the difference in TFWE takes on a U-shaped evolution trend, which first decreases in a fluctuation way and then increases monotonically. (3) Factors like industrial structure, import and export trade, environmental regulation and urbanization level have a positive impact on water efficiency, while resource endowment and economic level exhibit negative and nonlinear effects, respectively. Finally, several policy recommendations are made to improve water efficiency levels and promote water sustainability.
\end{abstract}

Keywords: total-factor water efficiency; Shephard water distance function; stochastic frontier analysis; China

\section{Introduction}

It is widely accepted that water resources are both irreplaceable natural resources and strategic economic resources. Water problems are especially challenging in China, as it has the largest population, fastest developing economy, scarce water resources, rising water demand and inadequate governance [1]. With the rapid development of China's economy and society, water issues have become the main bottleneck for the sustainable development of the country [2]. In China, water resource shortages and water environment deterioration are the two major problems restricting water sustainability. It was stated that China's per capita water resource was only one-quarter of the world average in 2014 [3]. Furthermore, the limited water resources are in an unbalanced distribution, 81\% of which are distributed in the southern area of China [4]. Additionally, China is faced with a series of water environment problems such as groundwater level decline, water quality deterioration, water 
eutrophication and biodiversity reduction [5]. What is more, water supply system safety is another important issue that should be included in water management [6-8].

In view of the tremendous challenges from water resources, the focal issue for current reform and research should be to promote sustainable utilization of water resources and sustainability of social economy. In this regard, water sustainability means water resource systems can contribute to the objectives of society, now, and in the future, while maintaining their ecological, environmental, and hydrological integrity [9]. Baumann et al. [10] proposed that efficient use can indeed promote sustainable use when it comes to water resources. Additionally, Bithas [11] stated that efficient use can be examined as a fundamental instrument in achieving water sustainability. In this context, the pursuit of water sustainability is consistent with the target of improving water efficiency.

In this context, the Chinese central government launched its most stringent water management plan known as the "3 Red Lines" water policy in 2011 to achieve sustainable use and management of water resources, which makes clear stipulations on total water consumption, water efficiency improvement and water pollution control [12]. Especially, water efficiency was planned, or close, to the world's advanced level by $2030[13,14]$. Actually, with the obtained water efficiency scores, we can understand the efficiency of water resource utilization in various regions and note the trends in efficiency changes [15]. Meanwhile, the determinants for regional differences in water efficiency could help policymakers focus on key factors when formulating relevant policies and measures. As such, the knowledge of water efficiency and its determinants can provide critical information for water policy formulation.

Water efficiency was first defined as the economic value of products produced per unit of water usage [16], which indicates how efficient the economic activity is with respect to its impact on the water environment. Following this definition, many researchers have measured the water efficiency in agriculture and economy-wide levels [17-24]. For instance, Mo et al. [18] used crop yields per unit water consumption to examine water use efficiency and its impact on agriculture in North China Plain. Li et al. [23] investigated the regional differences of water use efficiency in China by using a series of economy-water indices. However, the water efficiency indicators in the above literature all belong to partial-factor efficiency, which only takes water into account as a single input to produce an output while neglecting other key inputs. In fact, water use alone as an input cannot produce any output, and it must be put together with other inputs (e.g., labor, capital) in order to produce economic output. Additionally, since substitution effects exist among different production factors, partial-factor water efficiency evaluation is not comprehensive enough and may, therefore, lead to misleading conclusions.

In a pioneering work, $\mathrm{Hu}$ et al. [25] incorporated water input into the total-factor production framework to construct an index of total-factor water efficiency (TFWE) which was defined as the ratio of optimal-to-actual water use. Data envelopment analysis (DEA) as a multi-factor efficiency assessment technique has been widely applied to deal with water efficiency evaluation issues [26-36]. For example, Wang et al. [28] employed a slacks-based measure approach to examine water use efficiency of regional industrial systems in China. Hu et al. [36] applied DEA to evaluate Chinese province-level water efficiency under environmental constraints. It should be noted that water efficiency analysis aims to not only evaluate the water efficiency of regions, but also reveal determinants for regional differences so that policymakers could focus on those factors when formulating policies and measures to improve water efficiency. Literature on the analysis of factors influencing water efficiency is abundant [15,37-43]. For instance, Ding et al. [42] and Wang et al. [43] both utilized the DEA-Tobit model to investigate water use efficiency and its contributing factors in China.

It is obvious that DEA has been widely applied to the TFWE analysis. Despite its strengths, DEA is a nonparametric technique that does not take statistical noises into consideration, which may make the results very sensitive to data quality and even result in biased efficiency estimates [44]. Besides, DEA cannot analyze the influencing factors of technical efficiency directly, so researchers have to adopt two-step methods such as the DEA-Tobit model to study water efficiency and its determinants [37-43]. In view of the deficiency of DEA in this field, some scholars have chosen the stochastic frontier 
analysis (SFA) approach based on distance function to study technical efficiency and its influencing factors. This approach can not only include statistical noises in technical efficiency measurement, but also perform a quantitative analysis on the influencing factors of technical efficiency. As such, the proposed approach in this paper can achieve the synchronous realization of measurement and determinant analysis of technical efficiency and is, therefore, described as the one-step method. As a typical parametric frontier, SFA is an approach where all observations are on both sides of the frontier and it is possible to separate between random errors and differences in inefficiency [45]. The SFA approach was developed by Aigner et al. [46] and has been widely used to the fields of energy and environmental efficiency evaluation [47-54]. Especially, $\mathrm{Xu}$ and Yang [49] employed the SFA model based on Shephard energy distance function to analyze the TFWE and its influencing factors in China during 2001-2010. Similarly, Xing et al. [54] adopted the SFA model based on Shephard ecological distance function to analyze regional eco-efficiency and its determinants in China during 2007-2015. Nevertheless, to our best knowledge, there are few studies analyzing the TFWE and its determinants based on the parametric distance function approach.

In this context, this paper proposes a parametric frontier approach to analyze the water efficiency performance and its influencing factors in China. The potential contributions we add to the existing literature could be summarized in three aspects. First, this paper introduces the Shephard water distance function considering environmental constraints to construct a water efficiency index. Second, taking into account statistical noises, this paper proposes a parametric distance function approach to compute water efficiency. Third, the proposed approach can implement the measurement and factor analysis of water efficiency synchronously. The rest of the paper is planned as follows. Section 2 introduces methods and materials. The steps for establishing TFWE index and the SFA model for calculating the index and its determinants are presented in this part. Section 3 presents the results and discussion by which we employ the proposed approach to study the TFWE of regions in China from 2000 to 2015. Section 4 draws conclusions and considers policy implications.

\section{Methods and Materials}

\subsection{Shephard Water Distance Function}

Consider a production process by which each DMU (i.e., each province in China) employs capital stock $(K)$, labor force $(L)$ and water resource $(W)$ as inputs to produce GDP $(Y)$ and waste water $(B)$ as the single desirable output and undesirable output, respectively. Conceptually, the production technology can be defined as:

$$
T=\{(K, L, W, Y, B):(K, L, W) \text { can produce }(Y, B)\}
$$

In production theory, $T$ is often assumed to satisfy the following properties: (1) Nothing can be produced without inputs; (2) $T$ is finite; (3) $T$ is bounded; (4) $T$ is convex.

Following the spirit of Shephard energy distance function developed by Zhou et al. [44] and Wu et al. [55], we define a Shephard sub-vector input distance function for water use (hereafter referred to as the Shephard water distance function) as:

$$
D_{w}(K, L, W, Y, B)=\sup \{\beta:(K, L, W / \beta, Y, B) \in T\}
$$

Equation (2) seeks to estimate the maximum potential reduction in $W$, while holding the input-output combination within the production technology as defined by Equation (1). It measures the degree to which water use can be reduced. As such, $W / D_{w}(K, L, W, Y, B)$ denotes the hypothetical 
water use. The total-factor water efficiency (TFWE), defined as the ratio of optimal-to-actual water use [25], can be computed with the following formula:

$$
\mathrm{TFWE}=\frac{W / D_{w}(K, L, W, Y, B)}{W}=\frac{1}{D_{w}(K, L, W, Y, B)}
$$

TFWE is equal to the reciprocal of the Shephard water distance function. The definition of TFWE implies that it is less than or equal to one and a higher score means a better water efficiency performance.

\subsection{SFA Estimation Model}

In empirical application, the Shephard water distance function can be estimated within a nonparametric or a parametric framework. DEA is a popular nonparametric technique which does not impose any functional form on the frontier, thereby avoiding model misspecification [56]. However, DEA does not take statistical noises into account, which makes the results obtained from DEA very sensitive to data quality. In light of the limitation, parametric frontier estimation with SFA has attracted increasing attention from researchers [47-54]. Here, we follow Du and Lin [53] to adopt the translog function to specify the Shephard water distance function, which can be described as:

$$
\begin{aligned}
\ln D_{w}^{t}( & \left.K_{i}^{t}, L_{i}^{t}, W_{i}^{t}, Y_{i}^{t}, B_{i}^{t}\right)=\beta_{0}+\beta_{k} \ln K_{i}^{t}+\beta_{l} \ln L_{i}^{t}+\beta_{w} \ln W_{i}^{t}+\beta_{y} \ln Y_{i}^{t}+\beta_{b} \ln B_{i}^{t} \\
& +\beta_{k k}\left(\ln K_{i}^{t}\right)^{2}+\beta_{l l}\left(\ln L_{i}^{t}\right)^{2}+\beta_{w w}\left(\ln W_{i}^{t}\right)^{2}+\beta_{y y}\left(\ln Y_{i}^{t}\right)^{2} \beta_{b b}\left(\ln B_{i}^{t}\right)^{2} \\
& +\beta_{k l} \ln K_{i}^{t} \ln L_{i}^{t}+\beta_{k w} \ln K_{i}^{t} \ln W_{i}^{t}+\beta_{k y} \ln K_{i}^{t} \ln Y_{i}^{t}+\beta_{k b} \ln K_{i}^{t} \ln B_{i}^{t} \\
& +\beta_{l w} \ln L_{i}^{t} \ln W_{i}^{t}+\beta_{l y} \ln L_{i}^{t} \ln Y_{i}^{t}+\beta_{l b} \ln L_{i}^{t} \ln B_{i}^{t} \\
& +\beta_{w y} \ln W_{i}^{t} \ln Y_{i}^{t}+\beta_{w b} \ln W_{i}^{t} \ln B_{i}^{t}+\beta_{y b} \ln Y_{i}^{t} \ln B_{i}^{t} \\
& +\beta_{t} t+\beta_{t t} t^{2}+\beta_{k t} t \ln K_{i}^{t}+\beta_{l t} t \ln L_{i}^{t}+\beta_{w t} t \ln W_{i}^{t}+\beta_{y t} t \ln Y_{i}^{t}+\beta_{b t} t \ln B_{i}^{t}+v_{i}^{t}
\end{aligned}
$$

where $v_{i}^{t}$ is a random variable accounting for statistical noises and it is assumed to obey the standard normal distribution. Each $\beta$ is the parameter to be estimated.

According to the property that the Shephard water distance function is linearly homogenous in water input, we have:

$$
D_{w}^{t}\left(K_{i}^{t}, L_{i}^{t}, W_{i}^{t}, Y_{i}^{t}, B_{i}^{t}\right)=W_{i}^{t} \times D_{w}^{t}\left(K_{i}^{t}, L_{i}^{t}, 1, Y_{i}^{t}, B_{i}^{t}\right)
$$

The proof of Equation (5) is presented as Equation (S1) in the Supplementary Materials.

Substituting Equations (5) into (4) and rearranging it, we obtain:

$$
\begin{aligned}
\ln D_{w}^{t}\left(K_{i}^{t},\right. & \left.L_{i}^{t}, W_{i}^{t}, Y_{i}^{t}, B_{i}^{t}\right)=\ln W_{i}^{t}+\beta_{0}+\beta_{k} \ln K_{i}^{t}+\beta_{l} \ln L_{i}^{t}+\beta_{y} \ln Y_{i}^{t}+\beta_{b} \ln B_{i}^{t} \\
& +\beta_{k k}\left(\ln K_{i}^{t}\right)^{2}+\beta_{l l}\left(\ln L_{i}^{t}\right)^{2}+\beta_{y y}\left(\ln Y_{i}^{t}\right)^{2}+\beta_{b b}\left(\ln B_{i}^{t}\right)^{2} \\
& +\beta_{k l} \ln K_{i}^{t} \ln L_{i}^{t}+\beta_{k y} \ln K_{i}^{t} \ln Y_{i}^{t}+\beta_{k b} \ln K_{i}^{t} \ln B_{i}^{t} \\
& +\beta_{l y} \ln L_{i}^{t} \ln Y_{i}^{t}+\beta_{l b} \ln L_{i}^{t} \ln B_{i}^{t}+\beta_{y b} \ln Y_{i}^{t} \ln B_{i}^{t} \\
& +\beta_{t} t+\beta_{t t} t^{2}+\beta_{k t} t \ln K_{i}^{t}+\beta_{l t} t \ln L_{i}^{t}+\beta_{y t} t \ln Y_{i}^{t}+\beta_{b t} t \ln B_{i}^{t}+v_{i}^{t}
\end{aligned}
$$

After simple transformation, Equation (6) becomes:

$$
\begin{aligned}
\ln \left(1 / W_{i}^{t}\right)= & \beta_{0}+\beta_{k} \ln K_{i}^{t}+\beta_{l} \ln L_{i}^{t}+\beta_{y} \ln Y_{i}^{t}+\beta_{b} \ln B_{i}^{t} \\
& +\beta_{k k}\left(\ln K_{i}^{t}\right)^{2}+\beta_{l l}\left(\ln L_{i}^{t}\right)^{2}+\beta_{y y}\left(\ln Y_{i}^{t}\right)^{2}+\beta_{b b}\left(\ln B_{i}^{t}\right)^{2} \\
& +\beta_{k l} \ln K_{i}^{t} \ln L_{i}^{t}+\beta_{k y} \ln K_{i}^{t} \ln Y_{i}^{t}+\beta_{k b} \ln K_{i}^{t} \ln B_{i}^{t} \\
& +\beta_{l y} \ln L_{i}^{t} \ln Y_{i}^{t}+\beta_{l b} \ln L_{i}^{t} \ln B_{i}^{t}+\beta_{y b} \ln Y_{i}^{t} \ln B_{i}^{t} \\
& +\beta_{t} t+\beta_{t t} t^{2}+\beta_{k t} t \ln K_{i}^{t}+\beta_{l t} t \ln L_{i}^{t}+\beta_{y t} t \ln Y_{i}^{t}+\beta_{b t} t \ln B_{i}^{t}+v_{i}^{t}-u_{i}^{t}
\end{aligned}
$$

where $u_{i}^{t} \equiv \ln D_{w}^{t}\left(K_{i}^{t}, L_{i}^{t}, W_{i}^{t}, Y_{i}^{t}, B_{i}^{t}\right)$ is a non-negative variable accounting for water inefficiency. 
As a result, we derive an SFA model presented as Equation (7) for computing the Shephard water distance function. In solving, the maximum likelihood technique is adopted to estimate the parameters in Equation (7). After the estimation of Equation (7), the water inefficiency component $\hat{u}_{i}$ of region $i$ can be obtained and the corresponding water efficiency can be further calculated with $T F W E_{i}=\exp \left(-\hat{u}_{i}\right)$. Meanwhile, $u_{i}^{t}$ is assumed to follow the distribution of $N\left(\mu_{i}^{t}, \sigma_{u}^{2}\right)$. Thus, the determinants of water efficiency can be analyzed with the following inefficiency equation:

$$
\mu_{i}^{t}=\delta_{0}+\sum_{p} z_{i p}^{t} \delta_{p}
$$

where $z_{i p}^{t}$ denotes the influencing factors of water inefficiency and each $\delta$ is the parameter to be estimated.

Notably, all the unknown parameters in Equations (7) and (8) can be computed by a one-step estimation. Therefore, it allows the measurement and determinants of water efficiency to be analyzed simultaneously.

\subsection{Materials}

\subsubsection{Variables Selection}

This paper selects five variables as the input-output indicators. Three variables of capital stock $(K)$, labor force $(L)$ and water use $(W)$ serve as inputs, while GDP $(Y)$ and wastewater discharge $(B)$ are taken as the single desirable output and undesirable output, respectively. As there are no official statistics on capital stock in China, the data are estimated by the perpetual inventory method as described by Equation (9):

$$
K_{i t}=K_{i t-1}\left(1-\delta_{i}\right)+I_{i t}
$$

where $K_{i t}$ and $K_{i t-1}$ denote the capital stock of region $i$ in year $t$ and $t-1$, respectively. $I_{i t}$ denotes the investment of region $i$ in year $t . \delta_{i}$ denotes the depreciation rate of region $i$.

Additionally, this paper selects six variables as the contributing factors of water efficiency from the aspects of economy, nature, government and society. The specific variables are described as follows:

1. Economic Level (EL). In the literature, economic development level and water use efficiency were found to show a U-shaped relationship. It implies that water efficiency decreases with the economic growth at the low-level stage of economic development, while the opposite situation will appear when the economy grows to a certain degree. This paper adopts per capita GDP (in 2000 constant price) to measure local economic level. Meanwhile, its quadratic form is also taken as an explanatory variable in the model to investigate its nonlinear impact on water efficiency [41].

2. Resource Endowment (RE). This paper adopts water resource supply per capital to measure the rich degree of local water resources. Actually, due to the existence of "Resource Curse", many studies revealed that there is a significantly negative relationship between water efficiency and resource endowment [42].

3. Industrial Structure (IS). Agricultural and industrial sectors are the largest water consumers in China. Thus, industrial transformation and upgrading is significant for improving water use efficiency [57]. This paper takes the proportion of value added of the tertiary industry to the total output as the measurement of local industrial structure.

4. Import and Export Trade (IET). The import and export demand of products with high water consumption and high pollutant emission would have effects of substitution and promotion on China's relevant industries, respectively [37]. As such, it may affect the water efficiency to a certain extent. This paper adopts the ratio of imports to exports as the measurement of import and export trade.

5. Environmental Regulation (ER). This can help regulate the utilization behavior of water users, restrict the discharge of wastewater and stimulate technological innovation to reduce water use 
intensity [58]. According to Shen and Liu [59], we use the following indicator to measure local environmental regulation intensity:

$$
\mathrm{ER}=\frac{\mathrm{IPCI}}{\mathrm{GIP}} / \frac{\mathrm{GIP}}{\mathrm{GDP}}
$$

where IPCI denotes the investment in industrial pollution control and GIP denotes gross industrial product. The advantage of this index is to make use of GIP/GDP to modify the traditional environmental regulation index, and it can avoid the effect of regional industrial structure differences on the measurement of environmental regulation.

6. Urbanization Level (UL). The city is a symbol of modern civilization. It has better water supply facilities, water reuse technology and sewage treatment system, which can help improve local water use efficiency $[60,61]$. This paper adopts the share of urban population as the measurement of local urbanization level.

The variables and their units are summarized in Table 1.

Table 1. Summary of the inputs and outputs.

\begin{tabular}{|c|c|c|}
\hline Category & Variable & Unit \\
\hline \multirow{3}{*}{ Input } & Capital Stock & 100 million Yuan \\
\hline & Labor Employment & 10 thousand persons \\
\hline & Water Use & 100 million $\mathrm{m}^{3}$ \\
\hline Desirable Output & GDP & 100 million Yuan \\
\hline Undesirable Output & Wastewater Discharge & 10 thousand tons \\
\hline \multirow{6}{*}{ Influencing Factor } & Economic Level & 10 thousand Yuan/person \\
\hline & Resource Endowment & 10 thousand $\mathrm{m}^{3} /$ person \\
\hline & Industrial Structure & - \\
\hline & Import and Export Trade & - \\
\hline & Environmental Regulation & - \\
\hline & Urbanization Level & - \\
\hline
\end{tabular}

Note: Yuan denotes Chinese currency. The exchange rates to US Dollars and Euro are as follows: 1 Yuan $=0.1461$ US Dollars = 0.128 Euro, updated time: 11 August 2018 .

\subsubsection{Data Sources}

The data for the above variables were collected and compiled from China Statistical Yearbook, China Statistical Yearbook on Environment and Statistical Yearbooks of 30 provinces or cities from 2001 to 2016. Tibet, Hong Kong, Macao, and Taiwan were excluded in this paper due to data limitations. The monetary variables such as capital stock, GDP and economic level were deflated into 2000 constant price. Table 2 shows the summary statistics of the data.

Table 2. Descriptive statistics of the input and output variables (2000-2015).

\begin{tabular}{cccccc}
\hline Variable & N & Min. & Max. & Mean & Std. Dev. \\
\hline K & 480 & 174.40 & $45,455.92$ & 6633.52 & 7492.79 \\
L & 480 & 275.50 & 6760.40 & 2482.84 & 1661.77 \\
W & 480 & 19.18 & 591.30 & 193.08 & 135.66 \\
Y & 480 & 11131 & 911,523 & 189,795 & 153,880 \\
B & 480 & 263.59 & $14,916.39$ & 4097.13 & 3137.91 \\
EL & 480 & 0.2601 & 3.0230 & 0.9752 & 0.5411 \\
RE & 480 & 0.0159 & 0.2709 & 0.0517 & 0.0438 \\
IS & 480 & 0.2830 & 0.7965 & 0.4141 & 0.0788 \\
IET & 480 & 0.1242 & 5.8438 & 0.9717 & 0.8481 \\
ER & 480 & 0.0014 & 0.0852 & 0.0125 & 0.0115 \\
UL & 480 & 0.2320 & 0.8960 & 0.4885 & 0.1559 \\
\hline
\end{tabular}

Note: Std. dev. denotes the abbreviation of standard deviation, the same below. 


\section{Results and Discussion}

\subsection{TFWE Estimates}

We evaluated the TFWE of regions in China during 2000-2015 by solving Equation (7) with Frontier v4.1 (Centre for Efficiency and Productivity Analysis, Armidale, Australia), and the results were summarized in Table 3. It can be observed that Shandong had the highest average TFWE score of 0.933, and the following nine regions including Shanxi (0.907), Shanghai (0.893), Henan (0.885), Beijing (0.884), Chongqing (0.884), Qinghai (0.856), Shaanxi (0.844), Tianjin (0.828) and Guangdong (0.810) were all found with a score higher than 0.800 . On the other hand, Xinjiang was found to have the lowest value of 0.074 , and the following five regions such as Neimenggu (0.230), Heilongjiang (0.252), Guangxi (0.337), Jiangxi (0.370) and Ningxia (0.382) had a score lower than 0.400 . The above findings imply significant differences of TFWE among various regions in China.

Table 3. Summary statistics of the total-factor water efficiency (TFWE) results (2000-2015).

\begin{tabular}{|c|c|c|c|c|c|c|c|c|}
\hline Province & Abbreviation & Area & Min. & Max. & Median & Mean & Std. Dev. & Rank \\
\hline Beijing & $\mathrm{BEJ}$ & $E$ & 0.797 & 0.999 & 0.885 & 0.884 & 0.057 & 5 \\
\hline Tianjin & TIJ & E & 0.702 & 0.966 & 0.814 & 0.828 & 0.090 & 9 \\
\hline Hebei & HEB & E & 0.620 & 0.698 & 0.654 & 0.657 & 0.023 & 16 \\
\hline Liaoning & LIN & E & 0.582 & 0.751 & 0.719 & 0.704 & 0.044 & 14 \\
\hline Shanghai & $\mathrm{SHH}$ & E & 0.811 & 0.995 & 0.885 & 0.893 & 0.049 & 3 \\
\hline Jiangsu & JIS & E & 0.407 & 0.527 & 0.463 & 0.460 & 0.039 & 23 \\
\hline Zhejiang & $\mathrm{ZHJ}$ & $\mathrm{E}$ & 0.680 & 0.880 & 0.739 & 0.769 & 0.074 & 11 \\
\hline Fujian & FUJ & E & 0.520 & 0.716 & 0.567 & 0.573 & 0.042 & 18 \\
\hline Shandong & SHD & E & 0.879 & 0.997 & 0.916 & 0.933 & 0.041 & 1 \\
\hline Guangdong & GUD & E & 0.643 & 0.994 & 0.827 & 0.810 & 0.118 & 10 \\
\hline Hainan & HAN & E & 0.521 & 0.673 & 0.599 & 0.597 & 0.052 & 17 \\
\hline Shanxi & SHX & $\mathrm{C}$ & 0.758 & 0.998 & 0.943 & 0.907 & 0.080 & 2 \\
\hline Jilin & JIL & C & 0.360 & 0.563 & 0.469 & 0.460 & 0.066 & 22 \\
\hline Heilongjiang & HLJ & C & 0.198 & 0.318 & 0.253 & 0.252 & 0.041 & 28 \\
\hline Anhui & $\mathrm{ANH}$ & C & 0.462 & 0.679 & 0.524 & 0.547 & 0.068 & 19 \\
\hline Jiangxi & JIX & C & 0.328 & 0.421 & 0.369 & 0.370 & 0.027 & 26 \\
\hline Henan & HEN & C & 0.808 & 0.999 & 0.854 & 0.885 & 0.066 & 4 \\
\hline Hubei & HUB & C & 0.457 & 0.545 & 0.491 & 0.492 & 0.025 & 21 \\
\hline Hunan & HUN & $\mathrm{C}$ & 0.371 & 0.448 & 0.425 & 0.413 & 0.027 & 24 \\
\hline Neimenggu & NMG & W & 0.189 & 0.282 & 0.225 & 0.230 & 0.029 & 29 \\
\hline Guangxi & GUX & W & 0.246 & 0.453 & 0.322 & 0.337 & 0.067 & 27 \\
\hline Chongqing & CHQ & W & 0.741 & 0.996 & 0.875 & 0.884 & 0.088 & 6 \\
\hline Sichuan & SIC & W & 0.594 & 0.735 & 0.684 & 0.671 & 0.038 & 15 \\
\hline Guizhou & GUZ & W & 0.642 & 0.915 & 0.766 & 0.768 & 0.083 & 12 \\
\hline Yunnan & YUN & W & 0.646 & 0.814 & 0.725 & 0.723 & 0.056 & 13 \\
\hline Shaanxi & SAX & W & 0.707 & 0.976 & 0.836 & 0.844 & 0.085 & 8 \\
\hline Gansu & GAS & W & 0.434 & 0.647 & 0.508 & 0.516 & 0.067 & 20 \\
\hline Qinghai & QIH & W & 0.690 & 0.994 & 0.859 & 0.856 & 0.086 & 7 \\
\hline Ningxia & NIX & W & 0.245 & 0.473 & 0.404 & 0.382 & 0.070 & 25 \\
\hline Xinjiang & XIJ & W & 0.070 & 0.080 & 0.073 & 0.074 & 0.003 & 30 \\
\hline $\begin{array}{c}\text { Eastern } \\
\text { China }\end{array}$ & E & - & 0.700 & 0.793 & 0.731 & 0.737 & 0.027 & - \\
\hline $\begin{array}{c}\text { Central } \\
\text { China }\end{array}$ & C & - & 0.490 & 0.601 & 0.545 & 0.541 & 0.034 & - \\
\hline $\begin{array}{l}\text { Western } \\
\text { China }\end{array}$ & W & - & 0.525 & 0.610 & 0.575 & 0.571 & 0.027 & - \\
\hline China & - & - & 0.603 & 0.646 & 0.624 & 0.624 & 0.014 & - \\
\hline
\end{tabular}

Note: The column of Abbreviation denotes the corresponding abbreviated name of each region. Detailed efficiency estimates are listed in Table S1 in the Supplementary Materials.

In the larger area level, the average TFWE scores of Eastern, Middle and Western China were 0.737, 0.541 and 0.571, respectively, and that of China as a whole was 0.624 , showing an urgent need 
for improvement. By comparing the TFWE among the three areas, Middle China was found to have a collapse phenomenon in TFWE. In fact, due to the geographical location, the middle provinces are the first choice for undertaking the water- and pollution-intensive industries transferred from the eastern developed regions. Consequently, the trans-regional pollution transfer caused by the industry transfer is a significant reason for the low TFWE in Middle China.

For comparative purposes, we computed the Shephard water distance function in the nonparametric DEA framework, and the solving program is presented as Equation (S2) in the Supplementary Materials. Also, the TFWE results from the DEA model are listed in Table S2 in the Supplementary Materials. By comparison, we can observe that the choice between SFA and DEA would affect not only the TFWE scores but also the ranks. In addition, several regions had TFWE scores of unity when DEA was used, while this did not occur when SFA was used. This implies that SFA often has higher discriminating power than DEA, which might be considered as an advantage of SFA over DEA in benchmarking water efficiency. Additionally, Table 4 shows the Pearson and Spearman correlations of the two sets of TFWE scores obtained from SFA and DEA models. From this table, we can observe that both the Pearson and Spearman correlations between the two sets of TFWE results from SFA and DEA models were not very strong. This implies that SFA and DEA would possibly lead to different results in benchmarking water efficiency, which is consistent with the previous findings of Zhou et al. [44].

Table 4. Correlation between TFWE results obtained from different models.

\begin{tabular}{ccc}
\hline Model & DEA & SFA \\
\hline SFA & $0.640^{* *}\left(0.617^{* *}\right)$ & $1(1)$ \\
DEA & $1(1)$ & $0.640^{* *}\left(0.617^{* *}\right)$ \\
\hline
\end{tabular}

Note: ${ }^{*}$ Correlation is significant at the 0.01 level (2-tailed); the number in parenthesis is the Spearman rank correlation coefficient.

\subsection{Spatial-Temporal Evolution}

Figure 1 reveals the temporal trends of TFWE in China and its three areas. From the horizontal perspective, the development trajectories of the TFWE can be divided into three periods of 2000-2005, 2005-2010 and 2010-2015 by taking 2005 and 2010 as cut-off points (see Figure 1). More concisely, in the first period (2000-2005), China and its eastern area both showed an increasing trend, while Central and Western China fluctuated within a similar scope. In the second and third periods, China and its central and western areas were found to show a similar tendency by which TFWE first declined in a fluctuation way from 2005 to 2010 and then stayed range-bound during 2010-2015. With regards to Eastern China, the fluctuation and upward trends were observed in the two periods, respectively. From the vertical point of view, the TFWE of Eastern China was significantly higher than that of Middle and Western China for the whole period, as shown in Figure 1. This fully demonstrates that with economic and technological advantages, Eastern China can make use of water resources more effectively and efficiently, and thus closely approaches the production frontier.

Figure 2 indicates the spatial distribution of TFWE in China in 2000, 2005, 2010, and 2015. It can be observed that there existed significant differences of TFWE among various regions in China. Developed regions, such as Beijing and Shanghai, were found to have higher TFWE scores. However, there were those like Jiangsu, the efficiency of which was not consistent with its economic development level. Meanwhile, water-scarce regions such as Shanxi, Henan, Shandong and Shaanxi were found with higher efficiency, while the water-rich ones like Hunan and Jiangxi had a lower efficiency. This implies that the regional disparity of TFWE is a common result induced by multi-factors. 


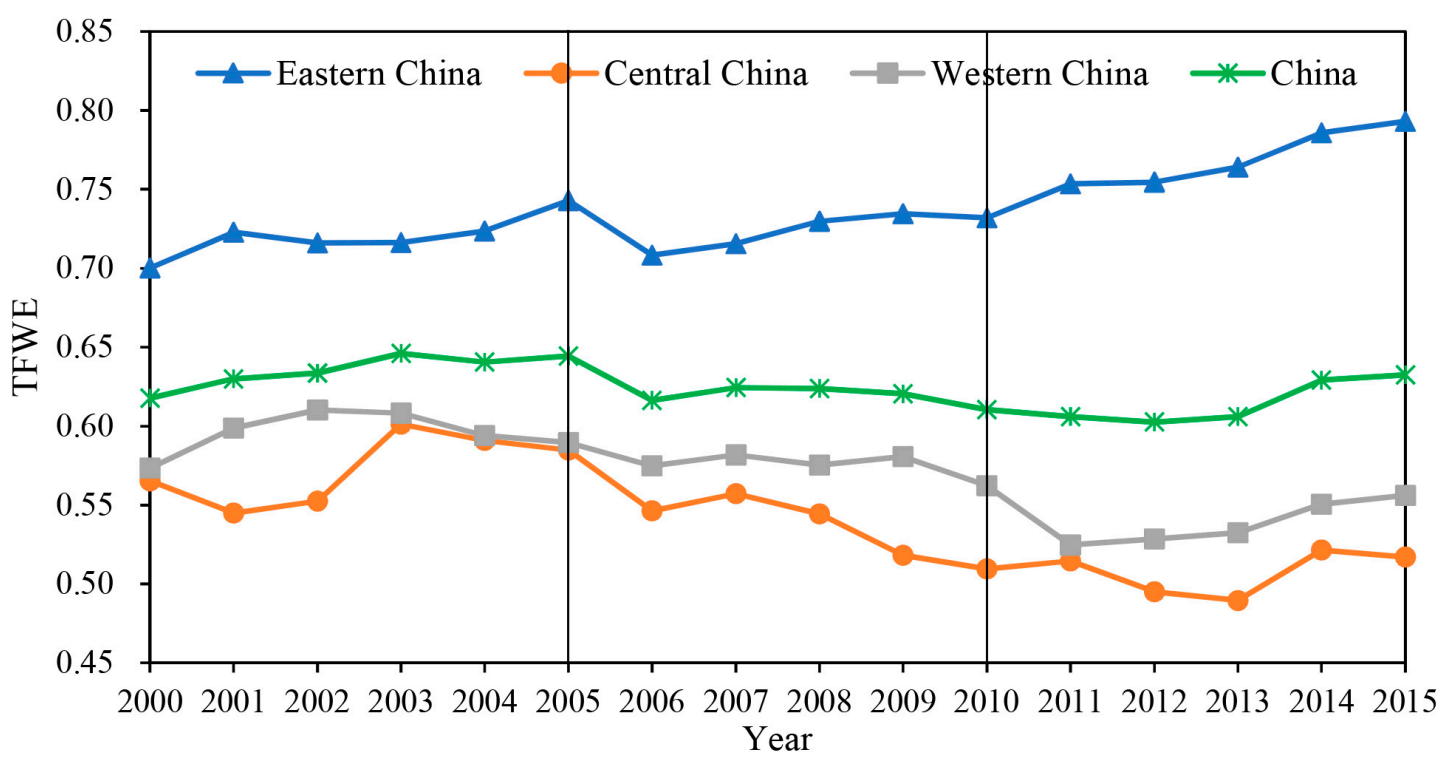

Figure 1. Trends of TFWE in China and its three areas from 2000 to 2015.
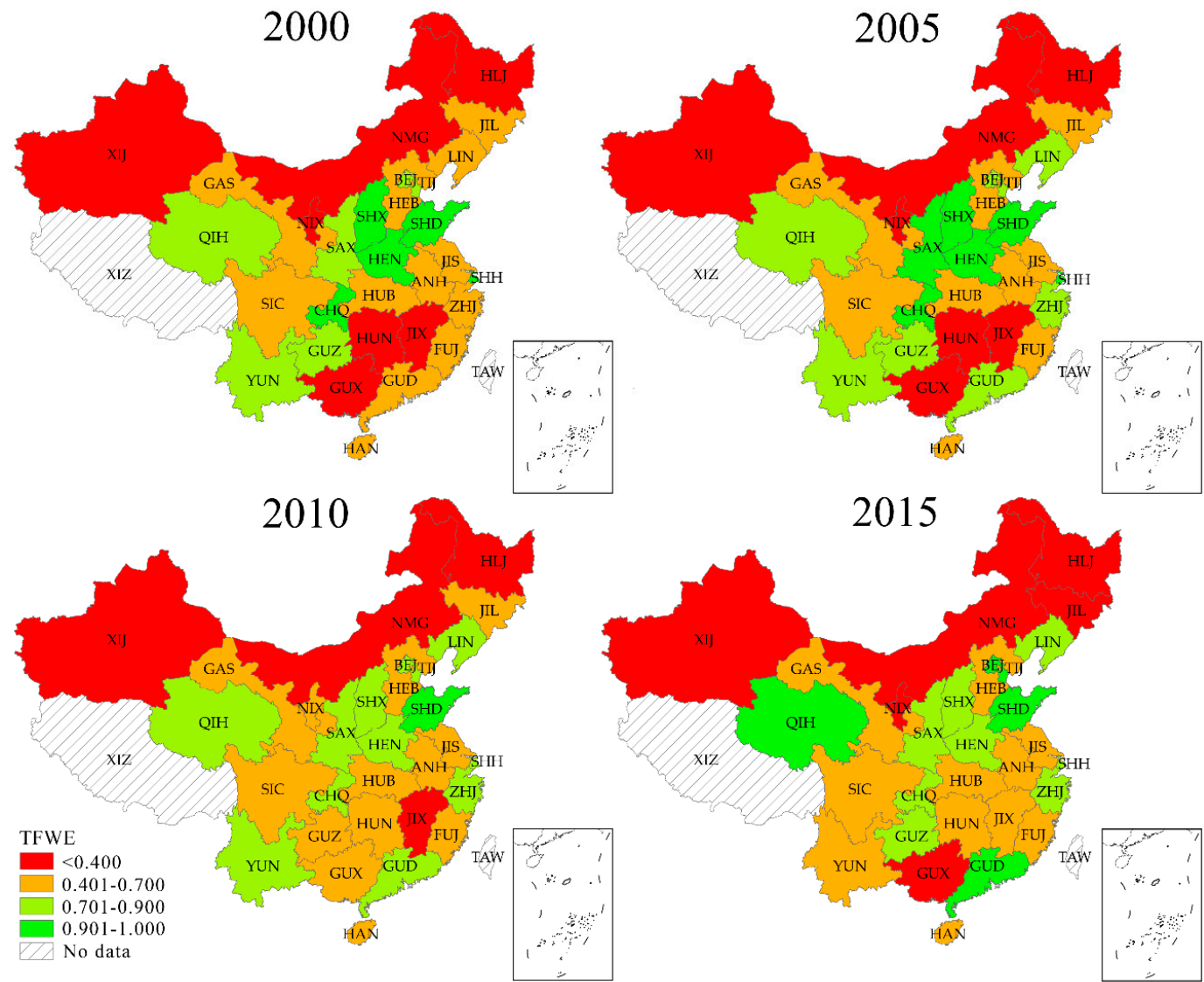

Figure 2. Spatial distribution of TFWE in China.

In order to investigate the evolution tendency of TFWE disparity in China, Figure 3 provides the changes in Std. dev. and variation coefficient (VC) of TFWE from 2000 to 2015. The two coefficients can measure the absolute and relative regional differences of TFWE, respectively. Their calculation formulas are presented as Equations (S3) and (S4) in the Supplementary Materials. From this figure, we can observe that the Std. dev. of TFWE took on a U-shaped evolution trend, by which it decreased in a fluctuation way from 2000 to 2011 and monotonically increased from 2011 to 2015. This implies that the absolutive disparity of TFWE showed an ascending tendency during 2000-2011, while the 
situation was opposite for the period of 2011-2015. Additionally, a similar evolution tendency for the VC of TFWE was also observed. That is to say, the relative disparity of TFWE also experienced a process of decreasing at first and then increasing. Taken together, the TFWE in China was apt to more spatial concentration before 2011, while became more regionally uneven after that point. In view of its enlarging trend, the Chinese government should take regional differences of TFWE as a major consideration when formulating water-saving policies.

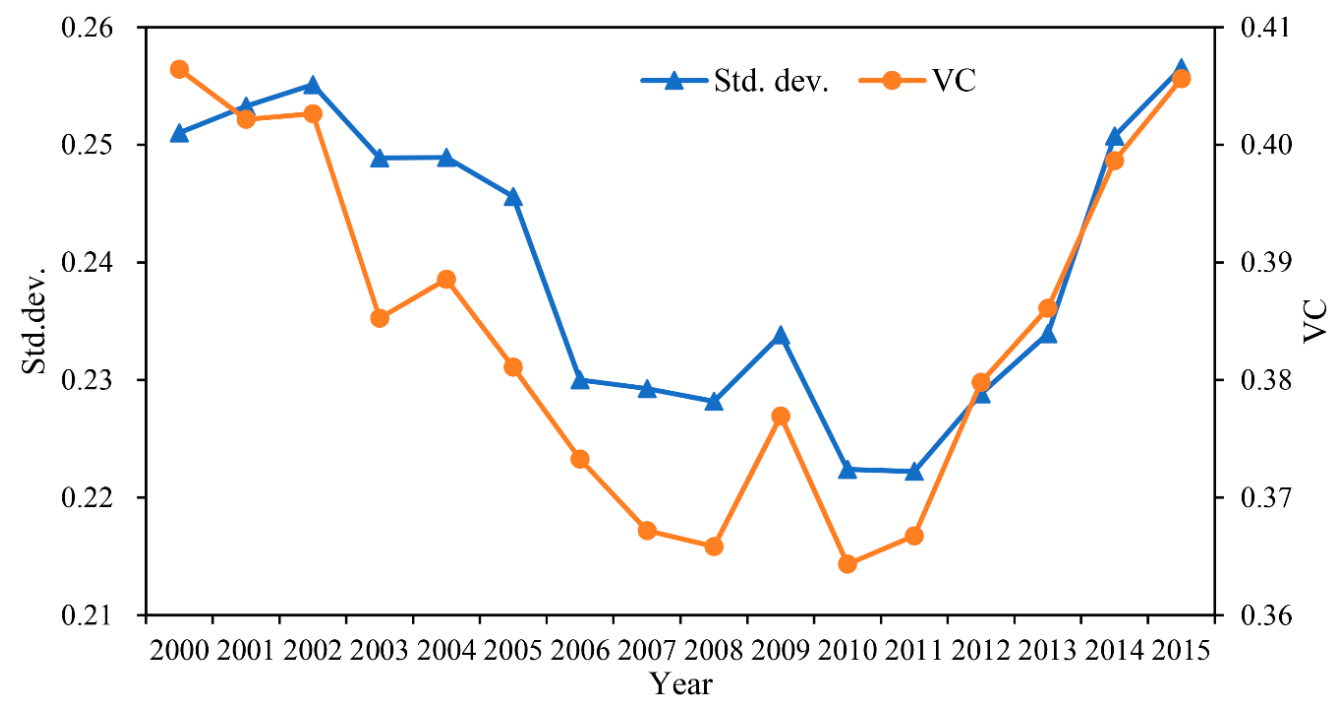

Figure 3. Changes of Std. dev. and variation coefficient (VC) of TFWE.

\subsection{Influencing Factors}

Water efficiency analysis aims to not only evaluate the water efficiency of regions but also reveal determinants for regional differences so that policymakers can focus on those factors when formulating policies and measures to improve local water efficiency. In this context, six influencing factors including economic level, resource endowment, industrial structure, import and export trade, environmental regulation and urbanization level were analyzed in this section. After the computation of Equation (7), we obtained the coefficient estimates of variables and the results are listed in Table 5.

Table 5. The estimation results of inefficiency equation.

\begin{tabular}{cccc}
\hline Variable & Coefficient & Std. Dev. & $t$-Ratio \\
\hline $\mathrm{C}$ & $-4.3159^{* * *}$ & 0.0508 & 9.05 \\
$\ln (\mathrm{EL})$ & $-0.3245^{* * *}$ & 0.0400 & -1.21 \\
$(\ln (\mathrm{EL}))^{2}$ & $-0.3082^{* * *}$ & 0.0254 & 12.15 \\
$\ln (\mathrm{IET})$ & $-0.0215^{* * *}$ & 0.0080 & 2.68 \\
$\ln (\mathrm{ER})$ & $-0.0199^{* * *}$ & 0.0065 & 3.08 \\
$\ln (\mathrm{RE})$ & $0.1288^{* *}$ & 0.0084 & 2.36 \\
$\ln (\mathrm{UL})$ & $-0.0732^{* *}$ & 0.0289 & 2.53 \\
$\ln (\mathrm{IS})$ & $-0.0708^{*}$ & 0.0434 & 1.63 \\
$\sigma^{2}$ & $0.0535^{* * *}$ & 0.0090 & 13.66 \\
$\gamma$ & $0.7498^{* * *}$ & 0.0801 & 8.07 \\
$\log$ likelihood function & 657.28 & - & - \\
LR test of the one-sided error & $1922.96^{* * *}$ & - & - \\
\hline
\end{tabular}

Note: ${ }^{* * *}, * *$ and $*$ denote the $1 \%, 5 \%$ and $10 \%$ significance levels, respectively. Due to the limited space, the other coefficient estimates are not listed here but provided in Table S3 in the Supplementary Materials.

For the primary and quadratic terms of variable $\ln (\mathrm{EL})$, we observed the former did not pass the $10 \%$ significance test while the latter had a positive impact on TFWE at the $1 \%$ significance levels. Thus, there existed a U-shaped relationship between economic level and TFWE, namely, with the growth of 
economic level, water efficiency first decreases and then increases. This may be attributed to the fact that the improvement of economic level was taken as the main task in the early period of economic development, while resources and environmental conservation were neglected. Consequently, water efficiency showed a downward trend. However, when the economy grows to a certain level, resource and environmental issues will bring obstacles to its further growth. In this case, people would follow resource-saving and environment-friendly modes to develop the economy and thus improve water efficiency.

For variable $\ln$ (IET), it was observed that import and export trade had a positive impact on water efficiency at $1 \%$ significance levels. As import and export trade is defined by the ratio of imports to exports, water efficiency was correlated positively with imports and negatively with exports. This is mainly because trade in agricultural and industrial goods that consume large quantities of water will result in the spatial transfer of water resources from export dependent regions to import dependent ones. This would increase burdens on the water resources supply of the former and alleviate that of the latter. As a result, imports and exports pose opposite impacts on water efficiency, and the ratio of imports to exports is positive.

From the coefficient of variable $\ln (\mathrm{ER})$, we observed that environmental regulation intensity had a positive effect on water efficiency at $1 \%$ significance levels. Actually, under the state of being restricted by rigid environmental behavioral rules, enterprises have to perfect their production technologies to save water and reduce pollution. Meanwhile, residents would also practice water recycling and re-use to improve water utilization efficiency.

For variable $\ln (\mathrm{RE})$, it was found that water resource endowment posed a negative effect on water efficiency at $5 \%$ significance levels. This is attributable to the impact of "Resource Curse" which implies that the more abundant water resources are in a region, the weaker awareness of water conservation local people have, thereby resulting in a lower water efficiency. For variable $\ln (\mathrm{UL})$, it was found that urbanization level posed a positive impact on water efficiency at $5 \%$ significance levels. In fact, urbanization would make agricultural water rapidly transferred to industrial or civil water-using departments. This means water resources would flow from rural to urban areas in the urbanization process. In addition, due to the fact that city has better water supply facilities, water reuse technologies and a sewage treatment system, the rural-to-urban water flows could help improve local water use efficiency and construct a water-saving industrial structure system. Additionally, urbanization development can create conditions for virtual water trade in international and domestic markets. In this case, water-intensive agricultural and industrial products can be imported from other provinces or countries instead of being self-produced, which may help reduce local water consumption to a certain extent. Taken together, urbanization can restrain the growth of the total amount of social and economic water consumption by promoting the optimal allocation of water resources.

From the coefficient of variable $\ln ($ IS), we observed that the industrial structure positively impacted water efficiency at $10 \%$ significance levels. Actually, agricultural and industrial sectors in China consume substantial water resources and emit considerable pollution. Moreover, water-saving and environmental protection technologies have not been widely used by agricultural production units and industrial enterprises. For example, in China's agricultural production, flood irrigation is often adopted, while sprinkling irrigation and drip irrigation are seldom used. Consequently, the water efficiency of these industries is at low levels. On the other hand, unlike the primary and secondary industries, tertiary industries consume much lower amounts of water resources and therefore are not highly sensitive to water supply. Thus, the growth of tertiary industries would promote water efficiency improvement. Notably, it is necessary to investigate whether the variable should be included in the model in the context of its marginal significance. To this end, we re-perform the model with the exclusion of the variable. By comparison, we can observe that the inclusion of this variable would indeed result in an improvement in overall model performance. Therefore, variable is worthy of discussion in this model. The regression results are listed in Table S4 in the Supplementary Materials and the detailed discussions are provided there as well. 


\section{Conclusions and Policy Implications}

In this paper, we propose a parametric distance function approach to estimate the water efficiency performance index and its influencing factors from the production efficiency viewpoint. Empirically, the proposed approach is applied to 30 regions of China from 2000 to 2015. The findings are as follows:

Both China overall and most of the regions still have room for improvement in terms of water efficiency. SFA and DEA would possibly lead to different results in benchmarking water efficiency. Moreover, SFA often has a higher discriminating power than DEA. Middle China was found to have a collapse phenomenon in TFWE, which may be attributed to the trans-regional pollution transfer caused by the industry transfer from Eastern China. There existed significant regional disparity in water efficiency of China and the difference was found to take on a U-shaped evolution trend. The regression results indicate that factors like industrial structure, import and export trade, environmental regulation and urbanization level have a positive impact on water efficiency, while resource endowment and economic level exhibit negative and nonlinear effects, respectively.

Based on the above findings, the following policy implications are provided as follows:

1. Due to the large regional differences in economic development level, water resources endowment, and water efficiency performance, the "one size fits all" solution should be avoided and differentiated regional water-saving strategies should therefore be formulated. For example, in terms of the province-level decomposition of national water-saving targets, an alternative scheme could be designed by assigning higher reducing targets to provinces with lower water efficiency scores, while assigning lower targets to those with higher scores.

2. In view of the existence of regional differences in location, transport, natural resources and ecological environment conditions, industrial structure exhibiting a positive impact on water efficiency improvement should be adjusted to suit measures to local conditions and give a full play to the superiority. Specifically, Eastern China should further strengthen the growth of the high-tech tertiary industry and orderly guide transfer industry to give a full play of its technology spillover effect. Middle and Central China should vigorously develop ecological agriculture and tourist industry by right of its geographical position and natural resources endowment. Meanwhile, based on resources and environment carrying capacity, local government should actively undertake transferring industries to promote the scientific upgrading of industrial structure.

3. Environmental regulation should be implemented on the principle of "common but differentiated responsibilities". Eastern China should strengthen environmental technological innovation to develop more efficient water saving and sewage treatment technologies. Besides, the government should formulate quantifiable wastewater reduction targets and further set up penalty mechanism to punish enterprises that are not qualified. Central and Western China should eliminate backward production capacity and encourage local enterprises to introduce advanced wastewater treatment technologies. In this regard, proper subsidies could be granted to enterprises which adopt environmental protection technologies and implement active measures of protection.

4. As the shortage of water resources per capita is serious, China should reduce the production of water-intensive products and services but turn to international imports from water rich countries, which is a feasible way to alleviate domestic water pressure. In urban water use, urbanization should be continuously accelerated to exert its scale benefit on reducing the cost of public water facilities and popularizing water-saving and pollution-control technologies. Additionally, the government should establish the reasonable water fee system, enhance the water saving propaganda, and promote the application of water saving instruments to regulate household water use behavior.

Nevertheless, this paper inevitably has some limitations. First, our proposed approach aims to measure static water efficiency performance based on cross-sectional data. Further research may be implemented to extend the proposed approach to study dynamic water productivity index based 
on panel data (refer to Equations (S5)-(S13) in the Supplementary Materials for more details). Also, whether the trans-regional pollution transfer results in the collapse phenomenon of Middle China in TFWE needs to be further investigated. Additionally, technological heterogeneity among various regions is truly a significant issue worthy of consideration and should be included in the model.

Supplementary Materials: The following are available online at http:/ / www.mdpi.com/2073-4441/10/10/1286/ s1. Table S1: TFWE estimation results from the SFA model. Table S2: TFWE estimation results from the DEA model. Table S3: Estimation results of $\beta$ parameters. Table S4: The estimation results of inefficiency equation excluding $\ln ($ IS $)$.

Author Contributions: J.Z. designed the research and drafted the manuscript; H.Z. collected the data and conducted the model simulation; Z.X. reviewed, commented on, and revised the manuscript. All authors have read and approved the final manuscript.

Funding: The authors would like to thank the financial supports provided by the National Natural Science Foundation of China (Grant No. 41471457), Social Science Foundation of Jiangsu Province (Grant No. 15GLD001), the Fundamental Research Funds for the Central Universities (Grant No. 2018B41314) and the joint PhD student program of China Scholarship Council (Grant No. 201806710015).

Acknowledgments: Special thanks to the two anonymous reviewers for their invaluable comments on an earlier version of this manuscript.

Conflicts of Interest: The authors declare no conflict of interest.

\section{References}

1. Liu, J.; Yang, W. Water Sustainability for China and Beyond. Science 2012, 337, 649-650. [CrossRef] [PubMed]

2. Xing, Z.C.; Wang, J.G.; Zhang, J. Expansion of Environmental Impact Assessment for Eco-efficiency Evaluation of China's Economic Sectors: An Economic Input-output based Frontier Approach. Sci. Total Environ. 2018, 635, 284-293. [CrossRef] [PubMed]

3. Zhao, L.S.; Sun, C.Z.; Zou, W. Analysis of the Relationship between Provincial Economic Growth and Water Footprint Intensity Convergence in China Based on Spatial Effect. Resour. Sci. 2013, 35, 2224-2231.

4. Fang, S.B.; Jia, R.F.; Tu, W.R.; Sun, Z.L. Research on the Influencing Factors of Comprehensive Water Consumption by Impulse Response Function Analysis. Water 2017, 9, 18. [CrossRef]

5. Yan, Z.; Sha, J.; Liu, B.; Tian, W.; Lu, J. An Ameliorative Whale Optimization Algorithm for Multi-Objective Optimal Allocation of Water Resources in Handan, China. Water 2018, 10, 87. [CrossRef]

6. Pietrucha-Urbanik, K. Failure analysis and assessment on the exemplary water supply network. Eng. Fail. Anal. 2015, 57, 137-142. [CrossRef]

7. Pietrucha-Urbanik, K. Assessing the Costs of Losses Incurred as a Result of Failure. Adv. Intell. Syst. Comput. 2016, 470, 355-362.

8. Pietrucha-Urbanik, K.; Zelazko, A. Approaches to Assess Water Distribution Failure. Period. Polytech. Civ. Eng. 2017, 61, 632-639. [CrossRef]

9. Loucks, D.; Gladwell, J. Sustainability Criteria for Water Resource Systems; Cambridge University Press: Cambridge, UK, 1999.

10. Baumann, D.D.; Boland, J.J.; Hanemann, W.M. Urban Water Demand Management and Planning; Chemical Industry Press: Beijing, China, 2005.

11. Bithas, K. The Sustainable Residential Water Use: Sustainability, Efficiency and Social Equity. The European Experience. Ecol. Econ. 2008, 68, 221-229. [CrossRef]

12. The State Council of China. Opinions on the Implementation of the Strictest Water Resources Management System. 2012. Available online: http://www.gov.cn/zhuanti/2015-06/13/content_2878992.htm (accessed on 15 February 2012).

13. Huang, G. From Water-Constrained to Water-Driven Sustainable Development-A Case of Water Policy Impact Evaluation. Sustainability 2015, 7, 8950-8964. [CrossRef]

14. Zang, Z.; Zou, X.Q.; Xi, X.; Zhang, Y.; Zheng, D.F.; Sun, C.Z. Quantitative Characterization and Comprehensive Evaluation of Regional Water Resources Using the Three Red Lines Method. J. Geogr. Sci. 2016, 26, 397-414. [CrossRef]

15. Deng, G.Y.; Li, L.; Song, Y.N. Provincial Water Use Efficiency Measurement and Factor Analysis in China: Based on SBM-DEA Model. Ecol. Indic. 2016, 69, 12-18. [CrossRef] 
16. Marlow, R. Agriculture Water Use Efficiency in the United States. In Proceedings of the U.S./China Water Resources Management Conference, Tucson, AZ, USA, 19-23 April 1999.

17. Kaneko, S.; Tanaka, K.; Toyota, T.; Managi, S. Water Efficiency of Agricultural Production in China: Regional Comparison from 1999 to 2002. Int. J. Agric. Resour. Gov. Ecol. 2004, 3, 231-251. [CrossRef]

18. Mo, X.; Liu, S.; Lin, Z.; Xu, Y.; Xiang, Y.; McVicar, T.R. Prediction of Crop Yield, Water Consumption and Water Use Efficiency with an SVAT-crop Growth Model Using Remotely Sensed Data on the North China Plain. Ecol. Model. 2005, 183, 301-322. [CrossRef]

19. Huang, Y.L.; Chen, L.D.; Fu, B.J.; Huang, Z.L.; Gong, J. The Wheat Yields and Water-use Efficiency in the Loess Plateau: Straw Mulch and Irrigation Effects. Agric. Water Manag. 2005, 72, 209-222. [CrossRef]

20. Wang, X.Y.; Zhao, L.G. Water Efficiency and Influencing Factors of China's Agriculture: The SFA Analysis Based on Provincial Panel Data, 1997-2006. Issues Agric. Econ. 2008, 3, 10-17.

21. Chen, D.J. Structure Share and Efficiency Share of Industrial Water Consumption Intensity Change in China. China Popul. Resour. Environ. 2008, 18, 211-214.

22. Liu, Y.; Wang, Z.F.; Zhang, J.B. Analysis of Factors Influencing Agricultural Water Resources Efficiency. Econ. Probl. 2007, 6, 75-77.

23. Li, S.X.; Cheng, J.H.; Wu, Q.S. Regional Difference of the Efficiency of Water Usage in China. China Popul. Resour. Environ. 2008, 3, 215-220.

24. Velasco-Muñoz, J.F.; Aznar-Sánchez, J.A.; Belmonte-Ureña, L.J.; López-Serrano, M.J. Advances in Water Use Efficiency in Agriculture: A Bibliometric Analysis. Water 2018, 10, 377. [CrossRef]

25. Hu, J.L.; Wang, S.C.; Yeh, F.Y. Total-factor Water Efficiency of Regions in China. Resour. Policy 2006, 31, 217-230. [CrossRef]

26. Sun, C.Z.; Liu, Y.Y. Analysis of the Spatial-temporal Pattern of Water Resources Utilization Relative Efficiency based on DEA-ESDA in China. Resour. Sci. 2009, 31, 1696-1703.

27. Bian, Y.W.; Yan, S.; Xu, H. Efficiency Evaluation for Regional Urban Water Use and Wastewater Decontamination Systems in China: A DEA approach. Resour. Conserv. Recycl. 2014, 83, 15-23. [CrossRef]

28. Wang, Y.S.; Bian, Y.W.; Xu, H. Water Use Efficiency and Related Pollutants' Abatement Costs of Regional Industrial Systems in China: A Slacks-based Measure Approach. J. Clean. Prod. 2015, 101, 301-310. [CrossRef]

29. Gadanakis, Y.; Bennett, R.; Park, J. Improving Productivity and Water Use Efficiency: A Case Study of Farms in England. Agric. Water Manag. 2015, 160, 22-32. [CrossRef]

30. Shi, T.G.; Zhang, X.L.; Du, H.R.; Shi, H. Urban Water Resource Utilization Efficiency in China. Chin. Geogr. Sci. 2015, 25, 684-697. [CrossRef]

31. Cheng, C.L.; Peng, J.J.; Ho, M.C.; Liao, W.J.; Chern, S.J. Evaluation of Water Efficiency in Green Building in Taiwan. Water 2016, 8, 236. [CrossRef]

32. Molinos-Senante, M.; Donoso, G.; Sala-Garrido, R. Assessing the Efficiency of Chilean Water and Sewerage Companies Accounting for Uncertainty. Environ. Sci. Policy 2016, 61, 116-123. [CrossRef]

33. Ma, H.; Shi, C.; Chou, N.-T. China's Water Utilization Efficiency: An Analysis with Environmental Considerations. Sustainability 2016, 8, 516. [CrossRef]

34. He, D.; Gao, P.; Sun, Z.; Lau, Y.Y. Measuring Water Transport Efficiency in the Yangtze River Economic Zone, China. Sustainability 2017, 9, 2278. [CrossRef]

35. Yang, W.X.; Li, L.G. Analysis of Total Factor Efficiency of Water Resource and Energy in China: A Study Based on DEA-SBM Model. Sustainability 2017, 9, 1316. [CrossRef]

36. Hu, P.; Chen, N.; Li, Y.; Xie, Q. Efficiency Evaluation of Water Consumption in a Chinese Province-Level Region Based on Data Envelopment Analysis. Water 2018, 10, 793. [CrossRef]

37. Qian, W.J.; He, C.F. China's Regional Difference of Water Resource Use Efficiency and Influencing Factors. China Popul. Resour. Environ. 2011, 21, 54-60.

38. Ma, H.L.; Huang, D.C.; Zhang, J.G. Water Resource Utility Efficiency and Its Influencing Factors Considering Undesirable Goods. China Popul. Resour. Environ. 2012, 22, 35-42.

39. Bao, C.; Chen, X.J. Spatial Econometric Analysis on Influencing Factors of Water Consumption Efficiency in Urbanizing China. J. Geogr. Sci. 2017, 27, 1450-1462. [CrossRef]

40. Zhao, L.S.; Sun, C.Z.; Liu, F.C. Interprovincial Two-stage Water Resource Utilization Efficiency under Environmental Constraint and Spatial Spillover Effects in China. J. Clean. Prod. 2017, 164, 715-725. [CrossRef]

41. Song, M.L.; Wang, R.; Zeng, X.Q. Water Resources Utilization Efficiency and Influence Factors under Environmental Restrictions. J. Clean. Prod. 2018, 184, 611-621. [CrossRef] 
42. Ding, X.H.; He, J.H.; Wang, L.Y. Inter-provincial Water Resources Utilization Efficiency and Its Driving Factors Considering Undesirable Outputs: Based on SE-SBM and Tobit Model. China Popul. Resour. Environ. 2018, 28, 157-164.

43. Wang, S.; Zhou, L.; Wang, H.; Li, X. Water Use Efficiency and Its Influencing Factors in China: Based on the Data Envelopment Analysis (DEA)—Tobit Model. Water 2018, 10, 832. [CrossRef]

44. Zhou, P.; Ang, B.W.; Zhou, D.Q. Measuring Economy-wide Energy Efficiency Performance: A Parametric Frontier Approach. Appl. Energy 2012, 90, 196-200. [CrossRef]

45. Mendes, A.B.; Silva, E.; Santos, J. Efficiency Measures in the Agricultural Sector with Applications; Springer: Dordrecht, The Netherlands, 2013.

46. Aigner, D.; Lovell, C.; Schmidt, P. Formulation and Estimation of Stochastic Frontier Production Function Models. J. Econom. 1977, 6, 21-37. [CrossRef]

47. Karagiannis, G.; Tzouvelekas, V.; Xepapadeas, A. Measuring Irrigation Water Efficiency with A Stochastic Production Frontier: An Application to Greek out- of Season Vegetable Cultivation. Environ. Resour. Econ. 2003, 26, 57-72. [CrossRef]

48. Boyd, G.A. Estimating Plant Level Energy Efficiency with A Stochastic Frontier. Energy J. 2008, $29,23-43$. [CrossRef]

49. Xu, J.Q.; Yang, Y.H. Research on Inter-provincial Energy Efficiencies in China and the Determinants-SFA Method based on 2001-2010 Panel Data. J. Shanxi Financ. Econ. Univ. 2012, 34, 71-78.

50. Wang, Q.W.; Zhou, P.; Shen, N.; Wang, S.S. Measuring Carbon Dioxide Emission Performance in Chinese Provinces: A Parametric Approach. Renew. Sustain. Energy Rev. 2013, 21, 324-330. [CrossRef]

51. Lin, B.Q.; Du, K.R. Technology Gap and China's Regional Energy Efficiency: A Parametric Metafrontier Approach. Energy Econ. 2013, 40, 529-536. [CrossRef]

52. Lin, B.Q.; Du, K.R. Measuring Energy Efficiency under Heterogeneous Technologies Using a Latent Class Stochastic Frontier Approach: An Application to Chinese Energy Economy. Energy 2014, 76, 884-890. [CrossRef]

53. Du, K.R.; Lin, B.Q. International Comparison of Total-factor Energy Productivity Growth: A Parametric Malmquist Index Approach. Energy 2017, 118, 481-488. [CrossRef]

54. Xing, Z.C.; Wang, J.G.; Zhang, J. Research on Regional Total-factor Ecological Efficiency in China: Measurement and Determinants. China Popul. Resour. Environ. 2018, 28, 119-126.

55. Wu, F.; Fan, L.W.; Zhou, P.; Zhou, D.Q. Industrial Energy Efficiency with $\mathrm{CO}_{2}$ Emissions in China: A Nonparametric Analysis. Energy Policy 2012, 49, 164-172. [CrossRef]

56. Xing, Z.C.; Wang, J.G.; Zhang, J. Total-factor Ecological Efficiency and Productivity in Yangtze River Economic Belt, China: A Non-Parametric Distance Function Approach. J. Clean. Prod. 2018, 200, 844-857. [CrossRef]

57. Bai, M.; Zhou, S.; Zhao, M.; Yu, J. Water Use Efficiency Improvement against a Backdrop of Expanding City Agglomeration in Developing Countries-A Case Study on Industrial and Agricultural Water Use in the Bohai Bay Region of China. Water 2017, 9, 89. [CrossRef]

58. Zhang, F.; Song, X.N.; Xue, H.F.; Dong, H.Z. Decoupling Relationship and Dynamic Response between Industrial Water Intensity, Environmental Regulation and Technological Progress. China Popul. Resour. Environ. 2017, 27, 193-201.

59. Shen, N.; Liu, F.C. Can Intensive Environmental Regulation Promote Technological Innovation? Porter Hypothesis Reexamined. China Soft Sci. 2012, 4, 49-59.

60. Bao, C.; Fang, C.L. Interaction Mechanism and Control Modes on Urbanization and Water Resources Exploitation and Utilization. Urban Stud. 2010, 17, 19-23.

61. Ma, H.; Chou, N.-T.; Wang, L. Dynamic Coupling Analysis of Urbanization and Water Resource Utilization Systems in China. Sustainability 2016, 8, 1176. [CrossRef]

(C) 2018 by the authors. Licensee MDPI, Basel, Switzerland. This article is an open access article distributed under the terms and conditions of the Creative Commons Attribution (CC BY) license (http://creativecommons.org/licenses/by/4.0/). 